\title{
GEOMETRICAL STRUCTURE OF ILLUSTRATIONS IN ISLAMIC MANUSCRIPTS: A CASE STUDY OF KALILA AND DEMNA ILLUSTRATIONS
}

\author{
SAFAA S. JAHAMEH \\ Applied Science Private University, School of Art and Design, Jordan
}

\begin{abstract}
This study discusses the geometrical structure of Islamic illustrations. Many theories suggest that Islamic illustration uses particular structures, including those based on spirals and proportion; however, these theories generally only relate the structure of such illustrations to sacred Islamic symbolism without reviewing the craft of illustration or the skills of the illustrators. Many researchers studying Islamic manuscripts, including Deroche, who studied Islamic codicology, have instead highlighted the range of tools used in Islamic civilisation, pointing out that many geometrical tools, some of which are no longer extant, were used by book craftsmen, including multiple kinds of rulers (Mastara). Diverse studies have thus used geometrical analyses to study Islamic manuscripts; Polosin studied the geometry of an illuminated folio in a Quranic manuscript and found that Islamic craftsmen at that time were aware of geometry and page structure, while George studied early Quranic manuscripts and identified a structural system used in the design of Arabic calligraphy and page structure. These researchers also concluded that certain geometrical tools used by craftsmen in Islamic civilisation are unidentified today. This study thus explores the geometrical structure of Kalila and Demna illustration in Islamic manuscripts, these being examples of the key illustration types of two different time periods, the 14th century and the 16th century. This paper examines eight folios from each manuscript, analysing them geometrically both to ascertain any geometrical relationship between the manuscripts and to determine whether geometrical proportion was being used at the time of production. Moreover, the paper investigates any potential cues that may suggest the illustrators were using geometrical tools.

Keywords: illustrations, geometry, structure, proportion, Islamic manuscript, Islamic codicology.
\end{abstract}

\section{INTRODUCTION}

The term Islamic manuscript is used to describe any ancient handmade book made between the 7th and 19th centuries in Islamic regions, an area stretching from China in the east to Morocco in the west. The extended period of time that this covers and the multitude of different regions and surrounding cultures means that there are multiple influences on Islamic manuscripts that must be considered in any study of these works.

The Islamic manuscripts produced in the various Islamic civilisations were multiple and differed widely in style; the tools, techniques, and materials used also varied considerably. Islamic manuscripts include many types of Islamic art, including Arabic calligraphy, ornamentation, and illustrations, yet many of these types of manuscript required the use of structural tools and techniques to ensure that the text was applied perfectly and that they fitted together in the same page or folio.

Islamic codicology is a scientific branch that studies the tools and materials used in Islamic manuscripts; it was first introduced by Déroche et al. [1], who analysed the features of Islamic manuscripts by considering page layout structure and materials used, highlighting the knowledge gap concerning the structure and geometrical tools used in Islamic manuscripts. These missing tools, such as al Mastara, have previously been described in Islamic heritage philosophy such as the Al-Buzjany writings [2].

Geometry plays an essential role in Islamic civilisation as well as in Islamic art and it was clearly used in the development of Islamic patterns [3], Arabic calligraphy [4], and Islamic 
architecture [5], as well as in illustrations. Proportional geometry is the main structure used in Islamic civilisations, yet there is limited current knowledge about the application process used for these geometrical proportions. This work extends the question about the geometrical tools that were used in Islamic art, investigating the processes by and the ways in which geometry was used in Islamic art applications. There has to date been a lack of research studying and analysing the use of geometrical tools and techniques used in illustrations in Islamic manuscripts; this paper thus contributes to the body of knowledge about book crafts in Islamic civilisations.

Studying two manuscripts on the same topic made in two different time periods is the method selected to facilitate the development of a more in-depth perspective on the use of geometrical tools by exploring the proportion and use of rectangles within both manuscripts. This study thus determines whether particular proportions are used for the illustrations within a manuscript and whether this structure is applied repeatedly to different manuscripts from different periods and locations to explore proportional geometrical tools used in diverse illustrations and to explain the use of proportional geometry.

\section{ILLUSTRATIONS IN ISLAMIC MANUSCRIPTS}

Based on the breadth of Islamic civilisation, Islamic manuscripts are described as being of different styles; these include the Persian manuscript style, which refers to any manuscript produced in areas such as modern Iran, Afghanistan, parts of Iraq, and parts of Kazakhstan, and other types of local Islamic manuscript such as Turkish and Moroccan. However, Islamic manuscripts are not solely classifiable based on their geographical location; they may also be grouped based on the use of similar elements such as Arabic calligraphy or ornamentation, as used in particular in the decoration of Quranic manuscripts. Islamic manuscripts are also classifiable by the way that the manuscripts were made, including the papermaking techniques and the parchments used; they also frequently involve the use of precious materials such as gold, which is used to decorate illuminated Islamic manuscripts [6].

The examination of Islamic manuscripts can be divided into two sections. The first considers the structural manuscript, including elements such as page layout, page margins, the clear space between lines, and the use of geometrical shapes like squares and rectangles, while the second is concerned with non-structural manuscripts. This latter term refers to any manuscript that does not use structural tools, in which writing lines may be slanted, regular margins not observed, and in which there may be a marked absence of structured geometrical shapes.

The main source of illustrations is Islamic manuscripts, yet illustrations have always been studied individually, considered to be separate from Islamic manuscript studies and particularly distinct from Islamic codicology. The majority of illustrations have been identified as translation images of the script, and most illustrations use a 2D approach from a birds-eye perspective [7]. Many of the illustrations are also copied from previous works; for example, illustrations of Shahnam in Islamic manuscripts are all very similar, with 16th century illustrations being copied directly from those in 15 th century manuscripts. Given the long period that elapsed between the creation of several of these manuscripts, it is remarkable that the illustrators use the same colours and characters and even the same structure for the scene; however, different illustrators also clearly add the cultural and artistic influences of their own particular backgrounds.

Most illustrations can therefore be seen and recognised by the type of structure used in the manuscripts, often including buildings and architecture drawn with certain types of ornamentation, including geometrical shapes and the use of Arabic calligraphy decoration. However, it has also been argued that the illustrations themselves are structured based on the 
geometrical proportions of rectangles; this approach can be used to analyse illustrations and describe the structure of a scene by relating it to geometrical symbolism [8].

Although there are plentiful studies on illustrations, their scope has been largely limited to religious influence and pre-Islamic or surrounding cultural influences; this focus has affected the understanding of illustrations in Islamic civilisations, as well as limiting investigation into the history of Islamic illustrators and the painting techniques and tools used by craftsmen throughout these periods.

In addition to applying theory based on the analysis of rectangle proportions, illustrations have also been analysed based on the geometrical structure of spirals, which is also linked to Islamic beliefs [9]. Previous research has discussed the possibility of geometry being used in illustrations for religious and symbolic reasons, noting that geometry effects can be clearly discerned in Islamic manuscripts and in illustrations. Studying the use of geometry in Islamic manuscripts may also explain more about the tools and techniques used in Islamic manuscripts, while Islamic codicology can be used to provide insight into illustrations and produce new evidence regarding book craft.

\section{PROPORTIONAL GEOMETRY IN KALILA AND DEMNA}

Rectangle proportions were commonly used in Islamic art and architecture and this study therefore discusses the possible use of these geometrical proportional rectangles in illustration. In addition to considering the possible use of particular proportions in illustrations within the same manuscript, this paper also investigates whether these proportions are used in illustrations of the same topic in different manuscripts from diverse periods and locations. If it can be proved that proportional rectangles were used systematically throughout various eras, this would suggest that a common geometrical tool was used to structure the proportional rectangles used in Islamic book craft through the ages.

\subsection{The proportional rectangle}

Proportional geometry has an essential application in Islamic art in structuring Islamic patterns, which facilitates analysis of the structure of Islamic art. Five types of proportions are applied in Islamic art, whether for Islamic patterns or architecture: root 2, root 3, root 4, root 5 (Fig. 1) and the Golden Section (Fig. 2).

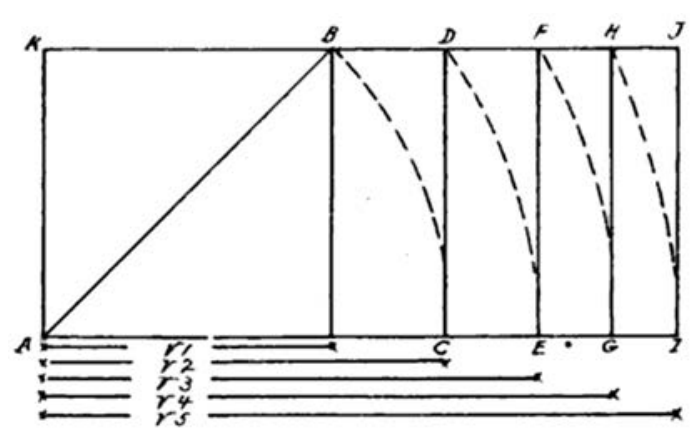

Figure 1: Proportional root rectangle [10].

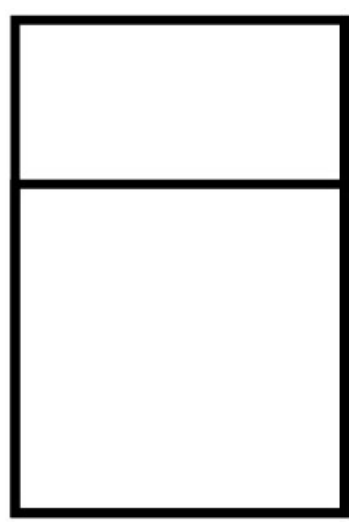

Figure 2: Golden Section rectangle. 


\subsection{Case study: Kalila and Demna}

Kalila and Demna [11] are a group of short stories written in Sanskrit and translated via the Pahlavi language to Arabic by Ibn al-Mukaffain in the 9th century. Manuscripts of these tales are considered excellent case studies for illustrations in Islamic manuscripts as they were produced in large numbers throughout Islamic history. Moreover, Kalila and Demna illustrations in Islamic manuscripts largely use similar scene structures with the application of different lines or shapes to the scene. Studying these illustrations therefore enables further investigation of the use of geometry and the techniques and geometrical tools in use in a given period.

To better explore the use of geometry in illustrations, the following criteria were used to select the manuscripts for this case study:

(a) Two manuscripts that were produced in different periods and locations.

(b) Both manuscripts cover the same topic.

(c) Physical information about the manuscripts such as the size of the pages is available.

(d) The illustrations are clear and available in an easily accessible high-resolution format.

(e) The selected illustrations feature a structured rectangle.

(f) Each manuscript illustrates many of the same topic scenes.

Based on these criteria, this study selected two Kalila and Demna manuscripts from different periods, Arabe 3465 [12], from the 14th century, and Arabe 3470 [13], from the 16th century; both of these are available from the Bibliotheque National de France (BNF). Eight folios were chosen from each manuscript that had illustrations describing the same scene in both manuscripts that used a structured rectangle format. Table 1 shows the manuscript number, scene number, and folio number for each comparison.

Table 1: Selected folios for the case study.

\begin{tabular}{|c|c|c|}
\hline Scene number & Folio number in MS Arabe 3465 & Folio number in MS Arabe 3470 \\
\hline 1 & Folio $116 \mathrm{v}$ & Folio $94 \mathrm{r}$ \\
\hline 2 & Folio $121 \mathrm{r}$ & Folio $98 \mathrm{v}$ \\
\hline 3 & Folio $34 \mathrm{r}$ & Folio $22 \mathrm{r}$ \\
\hline 4 & Folio $17 \mathrm{v}$ & Folio $10 \mathrm{r}$ \\
\hline 5 & Folio $80 \mathrm{v}$ & Folio $53 \mathrm{v}$ \\
\hline 6 & Folio $90 \mathrm{v}$ & Folio $69 \mathrm{v}$ \\
\hline 7 & Folio $130 \mathrm{v}$ & Folio $108 \mathrm{v}$ \\
\hline 8 & Folio $89 \mathrm{v}$ & Folio $68 \mathrm{v}$ \\
\hline
\end{tabular}

\subsection{Proportional detection method and analysis}

Adobe Illustrator software was used to detect any rectangles that appeared in the illustrations and these were then analysed in more detail to find any possible application of the proportional rectangle. Following this analysis, based on each scene represented in both manuscripts, the section for analysis as illustrated in the figures below, was set to represent the selected illustrations with the detected proportional rectangles. For each figure, the manuscript name and the folio number are given in the caption, and the main detection results for geometrical proportions are also given. 
3.3.1 Scene 1: proportional detection

Main result for Scene 1: Four Golden Section rectangles were detected in both Figs 3 and 4.

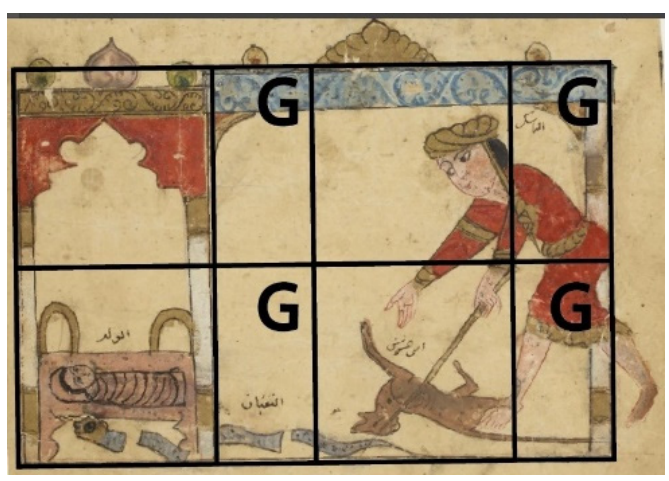

Figure 3: Proportional detection, Arabe 3465, Folio 116 v.

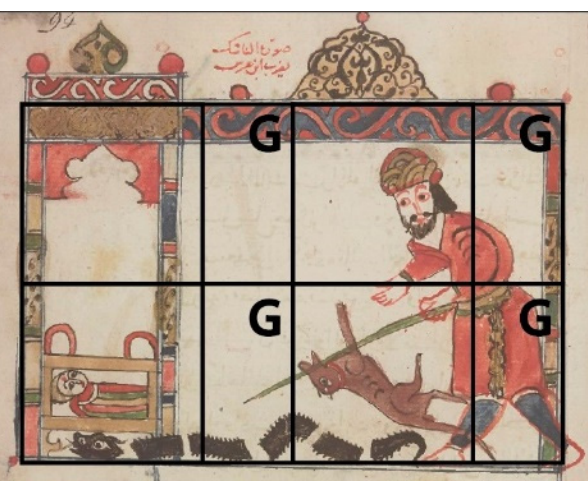

Figure 4: Proportional detection, Arabe 3470, Folio 94 r.

\subsubsection{Scene 2: proportional detection}

Main result for Scene 2: One Golden Section was detected in each of Figs 5 and 6.

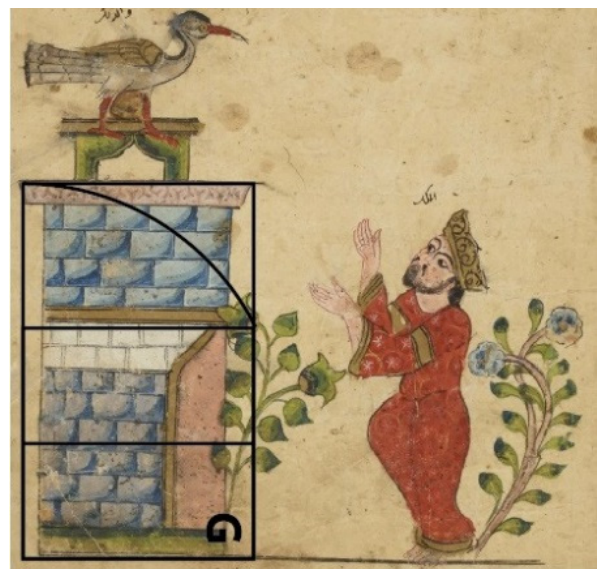

Figure 5: Proportional detection, Arabe 3465, Folio $121 \mathrm{r}$.

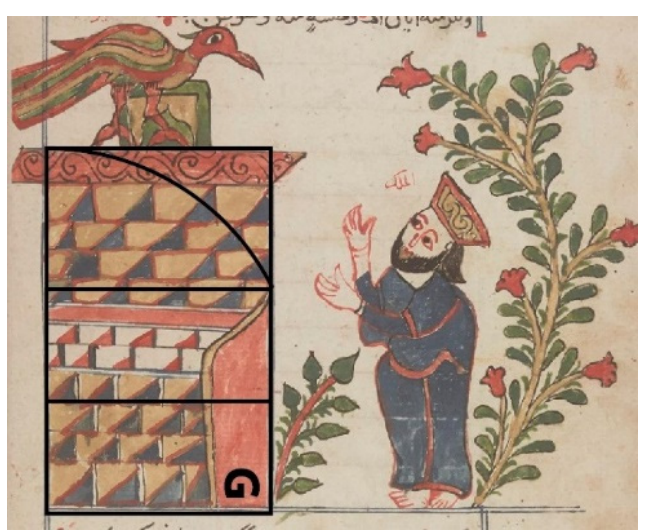

Figure 6: Proportional detection, Arabe 3470, Folio 98 v. 


\subsubsection{Scene 3: proportional detection}

Main result for Scene 3: One Golden Section was detected in both Figs 7 and 8.

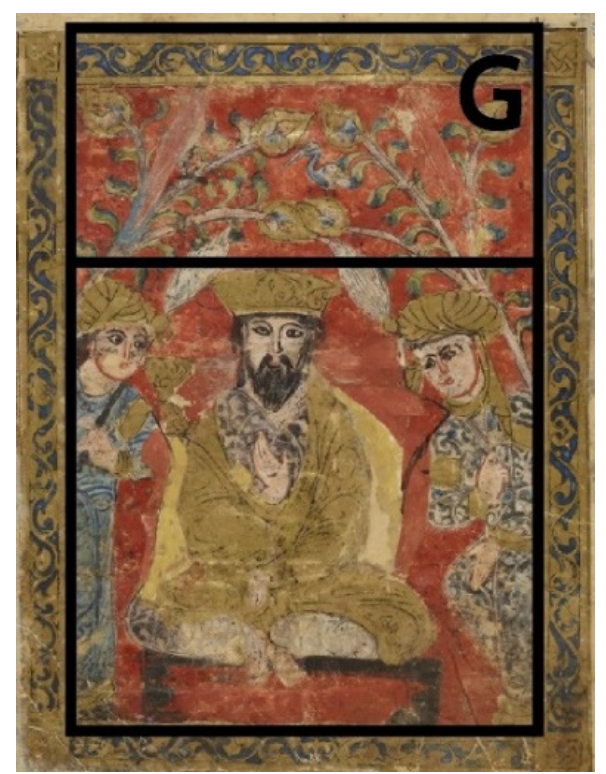

Figure 7: Proportional detection, Arabe 3465, Folio 34 r.

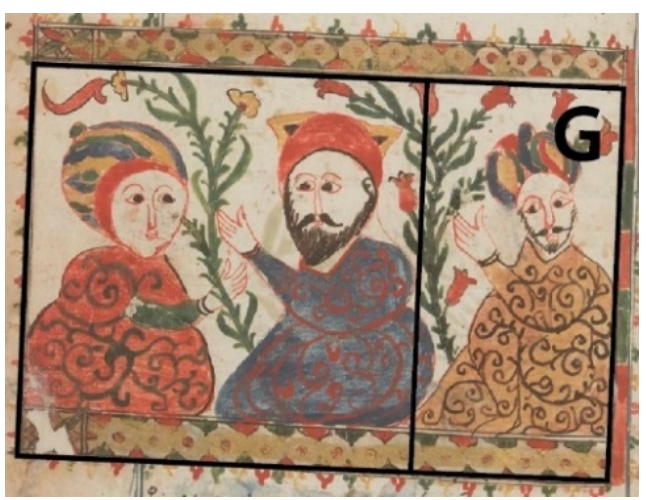

Figure 8: Proportional detection, Arabe 3470 , Folio 28 r.

3.3.4 Scene 4: proportional detection

Main result for Scene 4: One Golden Section was detected in Fig. 9 as well as in Fig. 10.

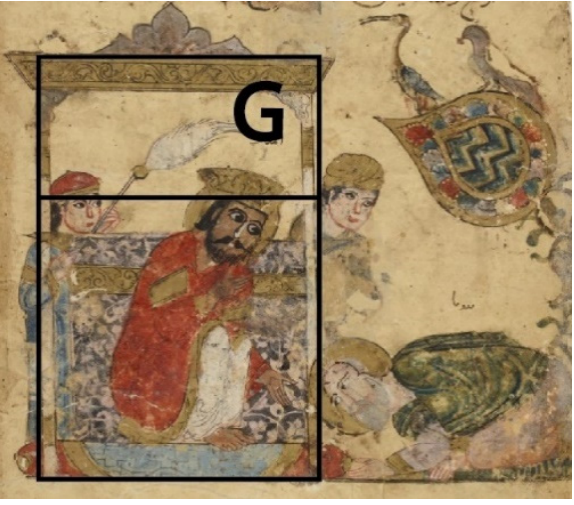

Figure 9: Proportional detection, Arabe 3465 , Folio $17 \mathrm{v}$.

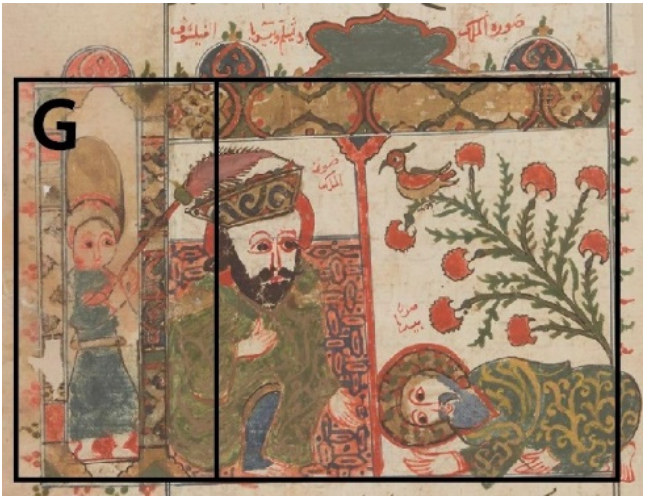

Figure 10: Proportional detection, Arabe 3470 , Folio $10 \mathrm{r}$. 
3.3.5 Scene 5: proportional detection

Main result for Scene 5: In Fig. 11, two Golden Sections were detected, while two Golden Sections are detected in Fig. 12.

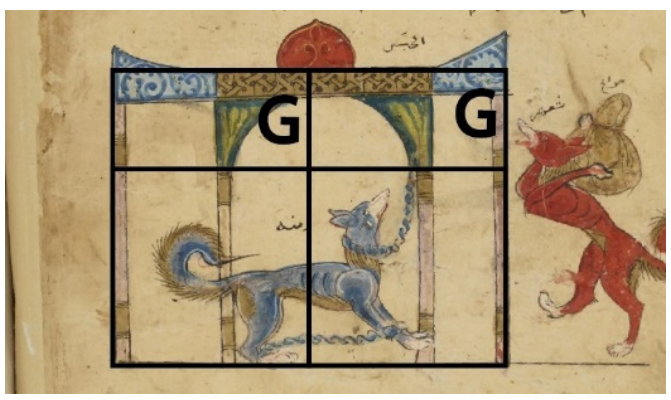

Figure 11: Proportional detection, Arabe Figure 12: Proportional detection, Arabe 3465 , Folio $80 \mathrm{v}$.

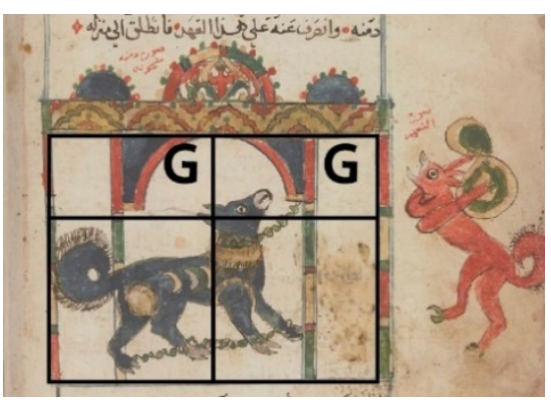

3470, Folio 53 v.

3.3.6 Scene 6: proportional detection

Main result for Scene 6: One Golden Section was detected in Fig. 13, while in Fig. 14, two Golden Sections were detected.

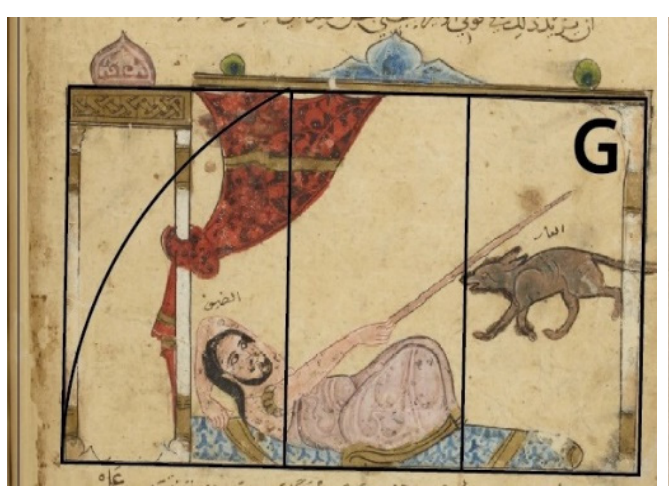

Figure 13: Proportional detection, Arabe 3465, Folio $90 \mathrm{v}$.

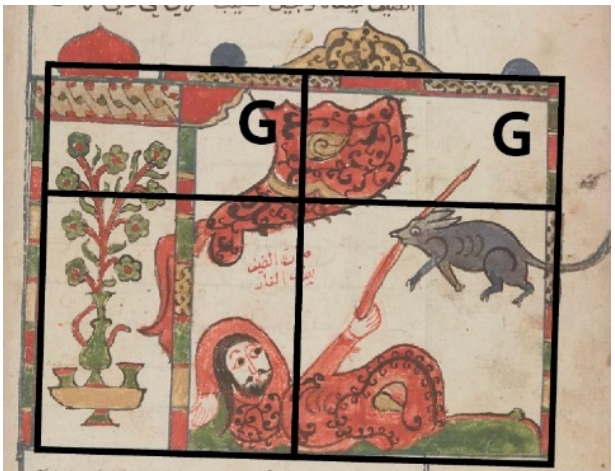

Figure 14: Proportional detection, Arabe 3470, Folio 69 v. 
3.3.7 Scene 7: Proportional detection

Main result for Scene 7: In Fig. 15, one Golden Section was detected, while two Golden Sections were detected in Fig. 16.

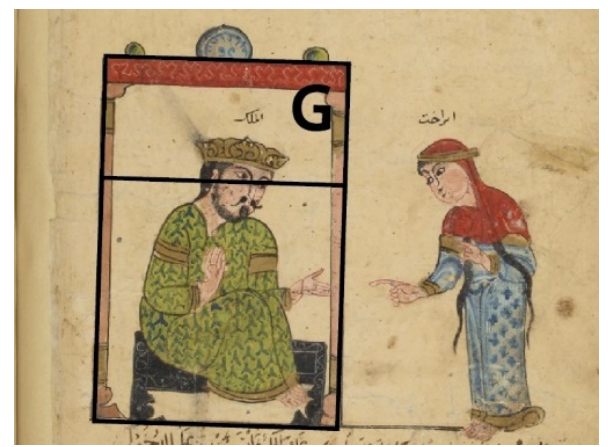

Figure 15: Proportional detection, Arabe Figure 16: 3465 , Folio 130 v.

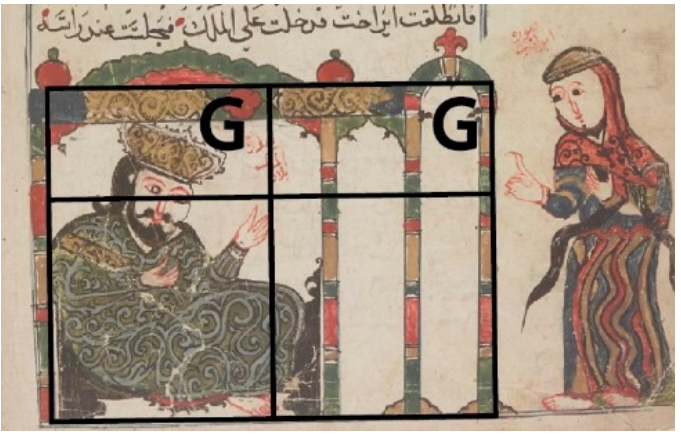

detection, Arabe 3470, Folio 108 v.

\subsubsection{Scene 8: Proportional detection}

Main results for Scene 8: One Golden Section was detected in Fig. 17, and two Golden Sections were detected in Fig. 18.

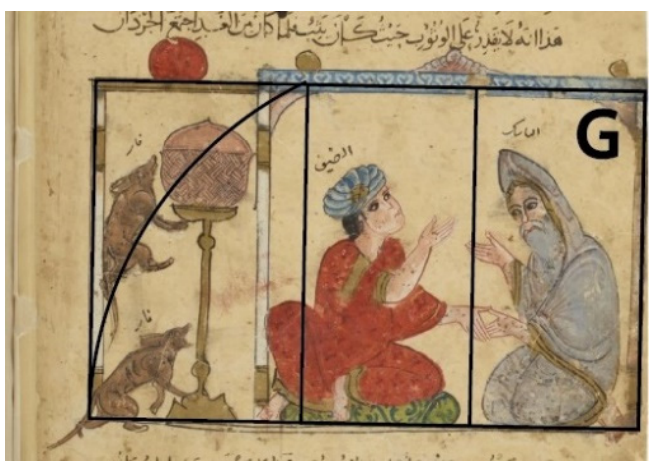

Figure 17: Proportional detection, Arabe Figure 18: Proportional detection, Arabe 3465, Folio 89 v.

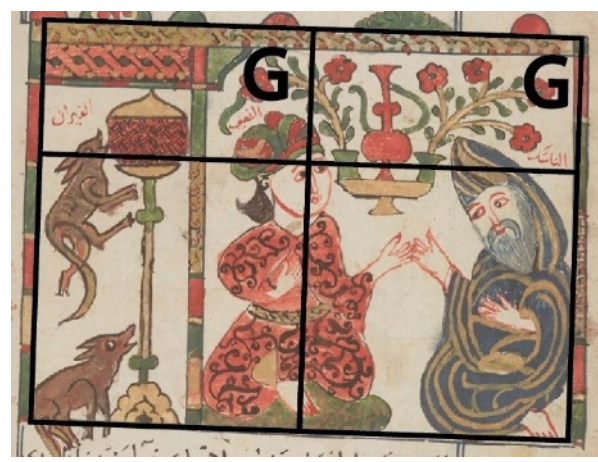

3470 , Folio 68 v.

\section{RESULTS AND DISCUSSION}

The results of the analysis revealed that both manuscripts used the same proportions, the Golden Section rectangle, in the same scenes but that these were applied in different ways; for example, the proportion might be repeated in different ways, such as being repeated four times in the illustration for one manuscript and twice in the other. 


\subsection{Proportional detection results}

For the Kalila and Demna manuscript Arabe 3465, in each case, the rectangle that holds the main illustrated scene or the most illustrations is structured based on either one Golden Section, two Golden Sections, or four Golden Section, with one illustration using four Golden Section rectangles; one illustration being based on two Golden Sections; and six illustrations being based on one Golden Section.

For the Kalila and Demna manuscript Arabe 3470, the main rectangle that holds the main illustrated scene or the most illustrations in each case is also structured based on either one Golden Section, two Golden Sections, or four Golden Sections, with one illustration being based on four Golden Section rectangles; four illustrations being based on two Golden Sections; and three illustrations being based on one Golden Section.

In both these manuscripts, the Golden Section was detected and applied within the same scenes, though this was applied differently in each manuscript. For the first matching scene, both illustrations have four Golden Section rectangles in the same location in the scene, as seen in Figs 3 and 4, while in the second matching scene, a Golden Section rectangle was detected in the same location in both manuscripts, as seen in Figs 5 and 6. In the third scene, a Golden Section was detected in the same location in both manuscripts but applied in a different way; in the Arabe 3465 manuscript, the Golden Section was applied vertically, as seen in Fig. 7, while in the Arabe 3470 manuscript, the Golden Section was applied horizontally, as seen in Fig. 8; a similar result was found in Scene 4, as seen in Figs 9 and 10 .

However, in Scene 5, two Golden Section rectangles were detected in the same location in both the illustrations, as seen in Figs 11 and 12, while Scenes 6 and 8 have the Golden Section applied in the same way, although the Golden Section rectangle is applied vertically in manuscript Arabe 3465 and horizontally in manuscript Arabe 3470, as seen in Figs 13 and 14 for Scene 6, and Figs 17 and 18 for Scene 8. Scenes 6 and 8 use two Golden Section rectangles while Scene 7 is structured as a single rectangle, as seen in Figs 15 and 16.

\subsection{Discussion}

This discussion is divided into four sections to further explore the geometrical analysis results and conclusions and to clarify the connections between the use of proportional rectangles and book craft in Islamic civilisation and the tools of design utilised to set those proportions.

1. Geometrical proportions in illustrations. The use of geometrical proportions in Islamic civilisations is widely recognised, including in the writings of Islamic philosophy scholars such as al-Kindi [14] and Greek philosophers including Euclid [15]. However, the use of these proportions has not been widely considered in the historical study of Islamic books, particularly with regard to illustrations. This paper sought to fill this gap by identifying and analysing the use of proportional rectangles in illustrations, the results of which suggest that the use of proportional rectangles was not only applied to Islamic architecture but also Islamic manuscripts and potentially to other crafts such as clothing and furniture in various Islamic civilisations. Moreover, it is highly possible that the use of new proportions was clearly understood within the book crafting communities of Islamic civilisations, as this paper found that two Golden Sections were structured within one rectangle, a pattern used in both manuscripts (Figs 11 and 12).

2. The proportional structure patterns in both Kalila and Demna manuscripts. Islamic patterns are prevalent in Islamic civilisations as a particular style of Islamic 
ornamentation, where pattern refers to shapes or forms repeated to create a particular and regular visual rhythm. Based on the analysis result, the proportional structures in these manuscripts resembled the use seen in particular areas in Arabe 3465 and in Arabe 3470, creating a new feature of pattern use. However, in this case, the pattern was used as way to structure the illustrations, thus making them more functional compared to the Islamic patterns used in architecture and Islamic manuscripts for decoration reasons. Further analysis suggested that the structure of these illustrations used the proportional rectangle to support patterns in both of the manuscripts. The proportional structure was used most particularly in key areas, as seen in Figs 5 and 6. Moreover, this finding was supported by the use of proportional structure as pattern both within and between illustrations made at different times.

3. Geometrical tools used in illustrations. As the same specific proportions were used in both the Arabe 3465 and Arabe 3470 manuscripts, this indicates that a particular tool was used to structure these proportions. Many types of geometrical tools, including rulers and measuring tools, were known in Islamic civilisations, and these were especially prominent in Islamic book craft. Deroche noticed, for example, that a physical ruler shaped like the Roman letter T, called the Mastara, was used as a page layout support, partitioning the page into columns in a manner useful for displaying lines of poetry in manuscripts. Units of measurement as well as proportions and justification as supplied by measuring tools have not previously been studied in relation to Arabic manuscripts; however, the results of this study suggest that certain key geometrical proportion tools were used in the Medieval ages in Europe and Middle East to structure the proportional rectangles used in illustrations (see Fig. 19). In addition to the Mastara, it is likely that tools such as compasses and rulers were used (see Fig. 20).

4. The craft of illustration. In this geometrical analysis, the application methods and the procedures of book craft in Islamic civilisation were examined through investigation of illustrations. As well as copying scenes, the illustration craft in Islamic civilisations used the geometrical proportions, both within the same manuscript and across different manuscripts to portray various ideas. It is possible that manuscript Arabe 3470 was copied from Arabe 3465, yet the case study revealed that Arabe 3465 has a different physical page size ( $280 \mathrm{~mm} \times 215 \mathrm{~mm})$ compared with Arabe 3470, which is $300 \times 210 \mathrm{~mm}$, yet the illustrators used the same application of the proportional rectangle across many pages, as seen in Figs 13 and 14 and in other folios. Although this paper found that the application differed, nonetheless, both manuscripts used the same proportional rectangle. This use of geometrical proportions indicates that there was awareness among illustrators that geometry could be used in book craft illustrations to satisfy the need for structure. As with the Arabic writings used in the same folio, this was intended to promote structure, rather than being required for religious symbolism.

In addition to the tools, technique, and materials, Islamic codicology requires examination of the proportional rectangle used in illustrations to provide more information about the structuralism of book craft; this also reveals more about the earliest manuscript sources and their influences on later manuscripts with the same topic.

\section{CONCLUSIONS}

It is clear that the proportional rectangle was widely used in Islamic illustration based on the case study in this paper, which features two manuscripts from different locations and periods that focus on the same topic. The geometrical proportion analysis in this case study showed 


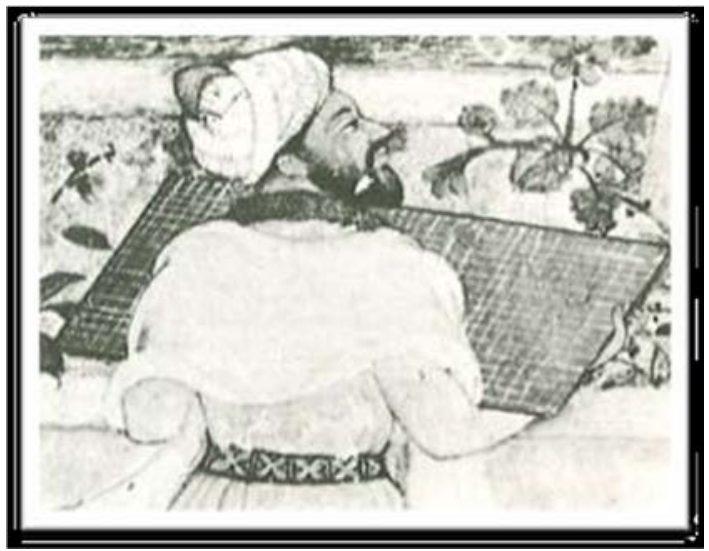

Figure 19: A book craftsman with a square grid in the workshop [16].

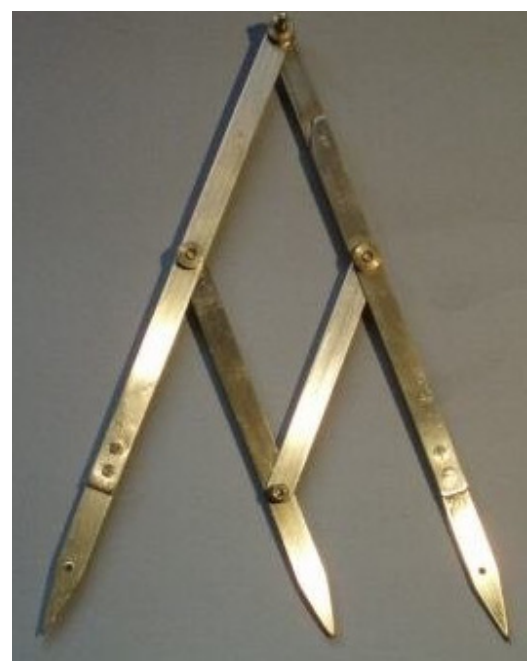

Figure 20: The Golden Ratio compass used in medieval times [17].

the use of a Golden Section rectangle in both manuscripts to support pattern structure, and this exact use of geometrical proportion also indicates the application of geometry in book crafting methods and techniques at those times.

The geometrical tools required to create proportional rectangles were known in medieval times, and it is highly likely that illustrators in these different periods used similar tools to set the Golden Sections of their illustrations. The tools and techniques used in such manuscripts can be studied using codicology; further research into Islamic codicology could thus be used to gather more information about illustrations, as distinct from Islamic manuscript studies.

\section{ACKNOWLEDGEMENTS}

The author wishes to thank the BNF (Bibliothèque nationale de France) and Gallica (https://gallica.bnf.fr) for providing the online high resolution images of the manuscripts. This research was supported by Applied Science Private University, Faculty of Art and Design, Amman, Jordan.

\section{REFERENCES}

[1] Déroche, F., Berthier, A., Waley, M.I., Dusinberre, D. \& Radzinowicz, D., Islamic Codicology: An Introduction to the Study of Manuscripts in Arabic Script, Al-Furqān Islamic Heritage Foundation: London, 2015.

[2] Gillispie, C., Dictionary of Scientific Biography, Charles Scribners Sons: New York, 1970.

[3] Critchlow, K., Islamic Patterns, Thames and Hudson: London, 1999.

[4] Mustafa, A. \& Sperl, S., The Cosmic Script, Thames and Hudson: London, 2014.

[5] Walls, A., Geometry and Architecture in Islamic Jerusalem, Scorpion: Buckhurst Hill, 1990. 
[6] Robinson, B., Islamic Painting and the Arts of the Book, Faber and Faber: London, 1976.

[7] Bloom, J. \& Blair, S., The Grove Encyclopedia of Islamic Art and Architecture, Oxford University Press: USA, 2009.

[8] Azzam, K. \& Suzuki, R., Arts and Crafts of the Islamic Lands, Thames and Hudson: London, 2013.

[9] Papadopoulo, A. \& Wolf, R., Islam and Muslim Art, Thames and Hudson: London, 1980.

[10] Hambidge, J., Dynamic Symmetry, Kessinger Publishing: New Haven, MT, 1920.

[11] Atıl, E., Kalila wa Dimna, Smithsonian Institution Press: Washington, DC, 1981.

[12] Kalīla wa Dimna, MS Arabe 3465, BnF: Paris.

[13] Kalīla wa Dimna, MS Arabe 3470, BnF: Paris.

[14] Al-Jubouri, I., History of Islamic Philosophy, Bright Pen: Hertford, 2004.

[15] Artmann, B., Euclid, Springer: New York, 2001.

[16] Necipoglu, G., The Topkapi Scroll, The Getty Center for the History of Art and the Humanities: Santa Monica, 1995.

[17] Ahmed, S., Golden mean compass - Construction, 2011. https://syedfawaz2002.wordpress.com/2011/03/16/golden-mean-compassconstruction/. Accessed on: 9 Feb. 2020. www.worthpoint.com/worthopedia/raregolden-ratio-brass-compass-divine-proportion. 